\title{
The evolution and design of the Concourse at the Sydney Opera House
}

\author{
OVE ARUP \& R. S. JENKINS
}

\section{Mr Ove Arup}

For many years now, architect-engineer collaboration has been normal practice in the building industry, and for many years the need for such collaboration and the form it should take have been the subject of innumerable papers and discussions in a general sort of way. But there is hardly a general way. Each case is different according to the nature of the job and the personalities involved. When every speaker or author speaks in general terms but has his own personal experiences in mind, misunderstandings are likely to arise.

73. I have often expressed the opinion that the many papers written about the design and execution of various jobs would gain in interest and usefulness to the reader if they set out to explain not only how the job was designed and constructed, but why this design was chosen, how it was arrived at, what alternative solutions were considered and rejected, and why, what snags were encountered in the execution and whether the author's experience had given him any ideas for improving the design.

74. It follows that if the job has grown out of a dialogue between client, architect and engineer, etc. it would be relevant to record such dialogue or trialogue. That this is very rarely done is understandable, for it is difficult and a somewhat dangerous thing to do-difficult because accurate reporting is difficult, architects or engineers cannot be expected to make notes in the heat of the battle, and trusting to memory is not very safe. It is dangerous because no two people will give the same account of an event in which both took part, and this could lead to undesirable arguments. Nevertheless, it would be useful, because it would throw some light on the different modes of architect-designer collaboration, and could thus further the understanding of the different points of view of architect and engineer.

75. One might say that structural engineers are concerned with economic stability and durability and architects with functional delight. The engineer deals with materials and forces of nature; in other words with facts which are not susceptible to persuasion, but demand invention firmly linked to accurate observation and logical deduction. Architecture in its narrow sense results from the manipulation of forms and spaces to create an environment in which man can move and live happily. The architect therefore must study man, his needs and his sensibilities, and he has no firm laws to guide him, only his own sensibility and imagination, which is therefore given free rein. The engineer makes models and prototypes to test their stability; the architect makes models to look at them and study his own reaction, or to impress or persuade clients. He needs to put his architectural vision across. If he presumes to tell people how they should live and what they should like, he must make them see things his way. Hence the need for beautiful models and seductive perspectives, for charm and salesmanship. The engineer has no such worries. Stability is desired by all and anyway not influenced by persuasion.

76. It is well known that propaganda, to be effective, need not pay much regard to facts. The temptation to improve on reality is therefore strong for architects. One might say that engineers represent rather dull and unrewarded virtue and the architect seductive charm.

77. We need a judicious combination of both. But it is not often that exceptional

Paper published: Proc. Instn civ. Engrs, 1968, 39 (April) 541-565. 
charm and exceptional virtue are combined in one person. So we must have collaboration between artistic and technological creators to satisfy man's needs.

78. This homily is only partly relevant to what follows. The particular collaboration described in the Paper was unusual, because the circumstances were unusual. Utzon was a perfectionist and in many people's view he sometimes went beyond what was reasonable. Perfectionists are a nuisance of course, but great art requires a passion for perfection.

\section{Mr R. S. Jenkins}

I am a believer in the principle of William of Occam. I therefore became involved in the Concourse at the analytical stage with some measure of inner conflict, but subscribed to the idea that what the architect wanted, right or wrong, had to be done. That is up to a point. I became somewhat heated on the business illustrated in Figs 12 and 13, which was happily resolved. I cannot help reflecting that had the architect stuck to the columns shown in Fig. 2, the whole thing could have been done in reinforced concrete without any jacking and wedging at a great saving in cost and trouble.

80. The main source of trouble was workmanship. It was very difficult to prevent the carpenters from using shuttering nails which they drove into green concrete to reduce bulging in the next pour. Anchorage blocks were their favourite points, so you will realize that when we got a cable stressed, our RE's were keen on getting it grouted as soon as possible.

81. The shuttering looked very nice while it was empty. Through loose wedges and ill-conceived ideas on stability for vibrated concrete there were bulgings and displacements in the first and second beams. This meant a great deal of cutting away and making good, all to appear as concrete straight from plywood shuttering.

82. This Paper was substantially written some time ago; the time when one had to make an excuse for doing the mathematics on an electronic digital computer, whereas it is now taken for granted. The reason for the long delay in publication was that it was hoped to furnish information on what happened when the extra permanent dead load was added about five years after concreting. Unfortunately, the results have not yet arrived.

\section{Mr A. L. Fielding}

If this project had been conceived five years earlier, its execution would not have been a practical proposition, but with new techniques and the use of the computer, the structure has emerged.

84. It is interesting to note the approach used on this project. By comparison all the Victorian bridges across the Thames were designed by engineers and the embellishments then added by architects. I believe that Lambeth Bridge was the first where the engineer and architect combined at the outset. Waterloo Bridge is another example of such collaboration. But in this structure the reverse has taken place, the architect conceived the design and the engineer was then called in to make it possible.

85. It would be of interest to learn if the Authors feel that the procedure adopted in this case has been justified from all aspects, or what they would suggest for the future.

\section{Mr G. P. Manning}

I was brought up on the stage, and I have known the basic principles of theatre design and theatre management since I was a schoolboy.

87. To produce a practical working theatre of this size a rectangular site is required, the length of which is about one and threequarters times its width. The design is begun by drawing a line across the middle dividing it into two equal parts. 
That line is the line of the proscenium. Half the site can be devoted to the auditorium, the foyer, entrances, stairs and bars, while the other half is required for the stage, back stage, scene dock, prop. room, dressing rooms, etc. Above the stage ample height is required to accommodate the flies and above the flies the grid. Many existing theatres fall somewhat below this standard of requirement behind the proscenium, but we are not here discussing a small provincial theatre built on a tight budget. We are discussing a building that was aimed to be a world-class opera house and the cultural Mecca of Australasia, and a project which will eventually cost some $£ 35$ million.

88. From the illustrations in the Paper, it can be seen that this particular site layout falls far short of these requirements. Large sums of money have been spent on constructing basements and purchasing various types of stage operating machinery, much of which has already been scrapped. I am quite convinced that no amount of stage-moving machinery will convert this building into a workable opera house.

89. A theatre is not run in an atmosphere of slide rules, drawings, specifications and computers. The world of the theatre is a world of stage hands, flats, sky-cloths and sticking plaster tops. I am sure that as a workable opera house, this scheme was dead from the start.

\section{Mr H. Kaylor, Consulting Engineer}

Reference is made to the use of an additive, Darex WRDA, in the concrete mix. Could the Authors tell us a little more about this?

91. It is also stated that a case could be made for the use of Freyssinet flat jacks, but could they not have been used in any case? After finishing the prestressing and after the grouting had been done the ship jacks were put in place and they created the thrust to overcome losses in the tie. I think this could have been achieved with Freyssinet flat jacks.

92. Why was the grouting of the cables completed and then some readjustment made after relaxation had taken place? Would it not have been practicable to complete the readjustment and finish up with something solid? So far as the grouting is concerned, could we be told which was used and how it was introduced?

\section{Professor S. R. Sparkes, Imperial College}

To me there are two interesting points about this concourse: firstly, the reason for it taking the form it did, secondly, the technical manner in which it was carried out. Mr Ove Arup has given reasons why this most unusual concourse took the form it did. It is sculptured engineering and I should like to see more of it. Would Mr Arup expound more his ideas about designing to meet the requirements of architects in this respect and the aesthetics behind it? Does he feel that this is a justifiable structure? $\mathrm{He}$ is meeting his Client's requirements but is he really convinced that this solution is right?

\section{An Architect, Mexico}

I quite agree with the ideas expressed by $\mathrm{Mr}$ Arup. Basically it is a matter of team work, particularly in a structure that has given rise to such problems from the technical point of view as this opera house.

95. When an architect expresses the first preliminary designs and first sketches of a structural idea, he must be perfectly conscious of what he is trying to accomplish. I believe that in good architectural work, the aesthetics are based on the structural character. That is something we cannot avoid. If it is a good work of architecture it must be honest so far as this is concerned, and one of the main things that an architect can accomplish is to give his work character through real expression of the structure itself. The work of many architects in Mexico who are concerned about this is well known. On the other hand, I am astonished to see what you are doing here 
with your techniques, and to see the many new techniques you have evolved. What $\mathrm{Mr}$ Arup and Mr Jenkins have done with the Sydney Opera House is first class. I think it is one of the masterpieces of architecture and engineering design of the century.

\section{Dr T. A. Wyatt, Imperial College}

It was interesting to note the reference in the Paper to measurement of statically indeterminate actions in the structure over quite long periods of time.

97. There are serious gaps in our knowledge of long-term changes in stress distribution in statically indeterminate structures, even for simpler structural types, particularly in concrete structures. Little work seems to have been done on this. The prestige value of the Opera House may have made it easier to get money for taking such measurements: they are of considerable interest and it is to be hoped that later results will be reported.

\section{Mr W. H. Wye, Bernard Engle \& Partners}

It is relatively easy to produce wonderful looking buildings, and judgement on the Opera House should be reserved until it is completed, and it can be seen how successfully it works as an opera house.

99. The engineers who have coped with the architect's requirements should take credit for any gratitude, but at the same time, the practice in these circumstances of putting the construction out to general tender is very wrong. The first requirement for a job of this nature was to choose an engineer who could cope with the requirements, and that was certainly done, but the same requirement should be demanded of the contractor. On many occasions I have had two buildings of the same calibre, and in one case the work goes very easily because the man building it has a feeling for the structure and organization and control, but in the other case, the building has been built according to the book, with the result that the job has gone badly. For a job of this nature and of this magnitude, it was a great pity that some of the members of the leading engineering and architectural institutions did not select the list of contractors, and ensure that nobody appeared on it who was not up to the job.

\section{The Chairman, Mr T. A. L. Paton}

Does Mr Arup think that a professional firm should resign from a job if they are not provided with a contractor whom they consider capable of doing it?

101. Bearing in mind the square footage and cube footage of the scheme, is its cost really extravagant? Is it not fairly reasonable, ignoring the original estimates which were obviously a long way out?

\section{Professor S. R. Sparkes}

I am particularly interested in the question of tests raised by Dr Wyatt.

103. I recall that Nervi designed a hangar that was erected in four different locations in Italy. The hangar roof was rectangular in plan and made of precast elements with site joints to form a shell grid. Deflexion readings were taken on all four hangars for the same condition of loading and the main deflexions varied from $5 \mathrm{~cm}$ to $10 \mathrm{~cm}$. Calculations could only give one value for the deflexions and yet these four supposedly identical hangars performed very differently when constructed. Would $\mathrm{Mr}$ Jenkins comment on the sort of comparison he would expect between his calculations and the actual behaviour of the concourse? Would he expect site measurements to be within $2 \%$ of his calculation, $50 \%$ or $100 \%$ ? If deflexions have been measured what modular ratio is indicated? Did the structure behave as expected under prestressing? 


\section{Mr Arup and Mr Jenkins}

The two questions raised by Mr Fielding and Professor Sparkes could perhaps be taken together because the first raises the question of whether it is right that the architect should design something and the engineer come in afterwards, and Professor Sparkes wants to know whether this is a justifiable structure.

105. In general, for the architect to design a structure and the engineer to come in to calculate it afterwards is obviously wrong. Design is a synthesis of ends and means, and no synthesis can be achieved by the successive application of two different minds. As, however, two different minds unfortunately are needed, it follows that they must as far as possible fuse into one to achieve the right synthesis, which means collaboration from as early a point as possible, and even collaboration is not enough, because that again requires that they should understand and respect each other's point of view, i.e. that the architect has some idea of structure, and that the engineer sympathizes with the architect's sculptural aims.

106. However, there can be no general rules for this kind of collaboration. Often the architect will know sufficient to make a sensible proposal which is acceptable as a structure and only needs to be detailed. Or the opposite can happen-the engineer proposes a structure which he thinks is structurally sound but which he also imagines would meet the architect's artistic requirements and which is also more or less accepted by the architect.

107. In between these two extremes there are all possible ways in which an intimate collaboration can bring forth ideas from both sides, and these contribute to a solution. Whether it is successful again depends on the result. A procedure which in itself is wrong in principle may very well in practice produce a good result, and this may have happened in this case.

108. That the result is more expensive than it need be if it is compared with a purely utilitarian structure is obvious. But if the aim is to produce an interesting structure with certain sculptural qualities, and if columns in the middle would impair the character of the whole concept, then it is a matter of opinion whether the money is well spent or not, and this of course entirely depends on the degree to which the hoped for impact has been produced.

109. The question then arises whether this effect could have been produced in a cheaper way by some other sculptural solution, for instance by arching the beams to reduce moments. This is of course very likely in view of the fact that the number of possible solutions is infinite, and they cannot all be investigated.

110. Personally I like the result and I think when the space is clear and the lighting is in, the effort spent on it will be shown to be justified.

111. Most of the troubles which arose on this job were really due to the pressure to get the work done before it was designed, and the inexperience of the Contractors in this particular kind of work. The quality is therefore not what it should have been. It would probably have been better to use precasting techniques, but we were strongly advised against it because we were informed that the Australian contractors were not familiar with it, and it would be far too expensive. Our experience on the superstructure later on disproved this, but a number of years had elapsed and we were in the latter case able to collaborate with a Contractor whom we ourselves had selected after a careful survey of the possibilities. This made all the difference, and to some degree leads on to the questions from $\mathrm{Mr}$ Wye and the Chairman.

112. As mentioned before, we are fully in agreement with Mr Wye about the importance of always having a selected list of contractors, and in the case of such jobs as the Concourse if would probably be better to have a selected contractor with whom it was possible to work for a number of months on the design before the execution was started. Construction should not be started before all the design problems have been resolved in detail. That this was done in the case of the roof structure was the main reason for its successful solution, but this is another story. That it was not done in 
the case of the Concourse was not because we did not want it, but because we were not in a strong enough position at that time to insist on it.

113. On the question of whether we should have resigned, it would have been very difficult for us to do so for the simple reason that we had no particular reason for objecting to this firm, and in fact I am sure they can do excellent work. The situation was difficult because the Contractors did not get the drawings in time, because we were forced to start on the site before we had the data which would enable us to make the drawings. The Contractor therefore had a number of legitimate grievances, and so had we.

114. In the case of the much more difficult roof structure we would have resigned if we had not been able to have the Contractor we had chosen, and we made that quite clear.

115. On the Chairman's question about costs, it is difficult to give an answer because one has nothing to compare it with. but it is probably right to say that the cost was reasonable considering the circumstances. We have already discussed the question of whether it is worth paying extra to produce this particular aesthetic effect, and we consider it $i$ on a building of this kind. That the cost was increased by the premature start has also been said. But apart from that it was done as economically as possible in the circumstances, and we certainly do not think that anybody made money out of it.

116. As regards $\mathrm{Mr}$ Manning's question, he may very well be right, but his criticism is entirely outside the scope of the Paper. It does not affect the Concourse roof at all, and it is not even a question about a structural problem but about theatre technique, which the Authors are unfortunately not competent to deal with. We were not concerned in the running of a theatre, but in the making of one. The equipment of a Design Office mentioned by Mr Manning $(\$ 89)$ all came into it. It is interesting to note, however, that when the Main Hall was going to be an Opera House the Siemen's punched-card system of controlling stage lighting and scenery was the method intended by the Architect.

117. The additive asked about by Mr Kaylor is manufactured in Australia and our people on the site examined it. It is much the same as concrete additives sometimes used in Britain. As it turned out, Freyssinet flat jacks would have been preferable in better contracting circumstances. They would have had to be kept fluid for many years, whereas we did have something solid in the wedge assemblies illustrated in Fig. 19. We should make it clear that we bought three ship jacks in all. They not only overcame loss in the tie, but also loss in the portal itself. The reason why it was desirable to grout the strand as soon as possible after prestressing is referred to in $\$ 80$.

118. Mr Kaylor also asked about grouting. This was done by means of a handoperated diaphragm pump. The maximum pressure required was generally $25 \mathrm{lb} /$ sq. in. A neat cement grout was used with a water : cement ratio of 0.53 . The only additive was a wetting agent, Lissapol $\mathrm{N}$, in a proportion of $0.05 \%$ to weight of cement. The grout was machine-mixed for a minimum time of $3 \mathrm{~min}$ and the result was passed through a fine mesh. The grout was introduced in a large number of places depending on the circumstances. We did examine some of the more critical positions by means of gamma ray photography, to confirm that the ducts were adequately filled.

119. In reply to Professor Sparkes, the calculations should be within $10-15 \%$ of the actual behaviour of the structure. One reassuring aspect was the calculated initial rise from shuttering at mid-span of $\frac{1}{2}$ in. Measurements gave almost the same figure. There were no site joints in this structure. In the Paper we dealt with the $E$ values used in calculations whose main objective was to prevent cracks and spalling by keeping the design within working stresses under all conditions. There are no cracks or spalls.

120. If there had been a great deal more knowledge available on concrete behaviour it might have been possible to prestress straight on to the structure without 
jacks and wedges. This would have made a substantial saving in cost. However, in our judgement, the state of knowledge required the elimination of the unknown factors as has been explained. The actual stresses in the cables could, of course, vary somewhat from those calculated and the losses we mentioned should be taken to be the average.

121. With regard to what happens when the permanent paving loads are added, we still lack information. We hope that a short report will be published when the information has been sorted out.

122. We express ouy thanks to Professor Roderick of the University of Sydney for his interest and help in the tests carried out on the strand. Thanks are also due to our RE for the Concourse, Mr A. M. Levy, not only for his organization of the prestressing and jacking, but also for his records and measurements furnishing the particular information given in the Paper. 